\title{
How to Mobilize your Library at Low Cost
}

\author{
Abarca Villoldo, Marta \\ Gabinete de Formación y Calidad de la Biblioteca, \\ Universitat Politècnica de València, \\ martabarca@gmail.com
}

\section{Lloret Salom, Andrés}

Biblioteca y Documentación Científica de la Universitat Politècnica de València, ANLLOSA@upvnet.upv.es

\section{Pons Chaigneau, David M.}

Biblioteca ETSID de la Universitat Politècnica de València, daponch@bib.upv.es

\section{Rubio Montero, Francisco José}

Biblioteca ETSII de la Universitat Politècnica de València, fcorumon@bib.upv.es

\section{Vallés Navarro, Raquel}

Biblioteca Facultad ADE - Topografía de la Universitat Politècnica de València, ravalna@bib.upv.es 


\begin{abstract}
The W3C defines the mobile web as a web in which users are able to access information from any location, regardless of the type of device used. In recent years, Internet access from mobile devices has grown considerably. This is due to many factors such as technological improvements of these devices, faster data transmission and lower connection costs.
\end{abstract}

This new context has led to the creation of various mobile web tools which offer a variety of features, such as adaptability of web websites, use of QR codes (Quick Response), geolocation tools, augmented reality and RFID technology just to name a few.

Technological advances give rise to new challenges. We should face this situation not as a threat or added workload, but as an opportunity to adapt the library to the new demands or needs of our users. This means that some of the services currently offered by the library will have to evolve, for example, with the creation of a mobile website or a mOPAC (mobile OPAC). New services could be offered, such as QR codes embedded in the catalog with bibliographical information, virtual reference through the mobile or geolocation of libraries.

This paper will first provide some basic and introductory information on the mobile web. It will then go on to describe some tools used in this area. In some cases, different options will be shown taking into account factors such as cost, for example. The aim here will be to provide an overview that will allow a given library to select the best tool according to their functions and their budgets. Finally, a list of library applications will be given, as well as their associated implementation processes in the Universitat Politècnica de València (UPV) library.

The ultimate goal of this paper is to encourage the creation and adaptation of services offered in libraries, placing special emphasis on the idea that a variety of services can be offered with just basic computer skills and a small staff, since in many cases these tools are available free of charge. In other words, these are low-cost tools that offer high returns to the user.

Key Words: mobile web; QR codes; mOPAC; augmented reality 


\section{Introduction}

It is a well-established fact that both the number of mobile devices and the information received from them is increasing, as indicated by the Internet Trends report published by Morgan Stanley (Meeker, Devitt \& Wu, 2010). Many people, in particular those known as "digital natives" use their smartphones not only to speak to others but to read their email messages, post messages on a social network, watch video or mobile TV and for other activities. However, searching for information is the main use given to mobile devices with Internet access (Ipsos, 2011).

For this reason, it should come as no surprise that a significant number of library users are showing an interest in accessing standard library services through their mobile device (Paterson \& Low, 2011), like searching for a book in the catalog, renewing or reserving a book, checking library opening times, etc. As with the advent of the World Wide Web, the adaptation of library services to this new channel of communication will involve several changes. As a matter of fact, libraries could take advantage of mobile devices and offer new library services which are normally used by library users outside of libraries, such as geolocation, QR codes, augmented reality, etc.

As suggested by the large number of studies published in the last two years from a variety of perspectives, there is a growing need for libraries to improve availability of services to library users. Several studies have revealed the importance of staff training in the field of mobile technology (Cummings, Merrill \& Borrelli, 2010), others explain how to create a mobile website (Iglesias \& Meesangnil, 2011), or discuss mobile information literacy (Havelka \& Verbovetskaya, 2012), to name just a few.

Some of these surveys focus on theory, while others don't always explain how to develop or adapt mobile services for users with little in the way of funding or computer skills. This paper adopts a more practical perspective, without losing sight of some key theoretical points, to explain how the UPV library has been "mobilized" using a minimum amount of funds and staff training. We will explain in detail how to create a mobile website, develop a mobile OPAC, QR code applications. This paper will also provide some information on geolocation and augmented reality. 


\section{The Mobile website}

\subsection{Presenting the problem}

Simply defined, a mobile website is an adaptation for mobile devices of the contents of a website (the library website in this case). At present, mobile browsers display a non-adapted website, which allows users access to the entire contents of the website offered by the UPV library. However, if the website remains as is, display issues arise forcing users to excessively rely on the scroll and zoom functions which in turn hamper or even obstruct the navigation process for users wishing to browse our website.

Many libraries have already developed a mobile website (Thomas, 2012), for instance, using a low-cost tool (Travis \& Tay, 2011) or using programming languages (Iglesias \& Meesangnil, 2011).

\subsection{Steps of mobile website development in four phases}

We will offer a step-by-step guide that will help librarians develop a mobile website in four phases: definition of content, creation, validation and user access to mobile website.

(1) Defining the content

Those users who access our website through a mobile device expect a quick and clear answer to their information needs. This step involves taking into account the limitations of mobile devices, particularly the small size of their screens. There are various types of content that must be included on a mobile website (Aldrich, 2010): mOPAC (Mobile OPAC, which is detailed below), university libraries' opening times, a list of the libraries of the university with basic information: their address, telephone, email...

In addition to that listed above, mobile websites typically include other content (Arroyo Vázquez, 2010) such as: news, bibliographical news, virtual reference service, access to electronic resources optimized for mobile devices, availability of library resources, study 
rooms, computers, etc., access to the mobile version of social tools: Twitter, Facebook, etc.

(2) Options of creating the mobile website Considering the list of best practices offered by W3C in relation to the creation of a mobile website [W3C, 2008], there are 3 available options: to do nothing, to use an automatic converter or to develop one from scratch (Arroyo Vázquez, 2009). These options are detailed below:

(a) Doing nothing (cost: $€ 0^{1}$ )

If you can't adapt your website or you believe that your users don't access the library through a mobile device, this option is for you.

(b) Using an automatic converter (cost: €0)

There are several free online tools that can be used to automatically convert our website to a mobile website. Some of these tools are MoFuse or Mobify.me

(c) Self-development (starting at $€ 0$ )

This option is the most convenient and most used by libraries who want to create a mobile website. It allows more flexibility, and depending on the option you choose, it costs little or nothing. There are several ways to do this, such as programming the website using a program language, using a free online service to adapt the website or designing an application for mobile devices. These options are described below 2.3. Special issues of self development with examples.

(3) Validating the mobile website

Once our mobile website is finished, we can use a validator to check it. This is an online tool (cost $€ 0$ ), which detects errors in our mobile website in order to correct them. An example of a validator is the W3C mobileOK Checker (http://validator.w3.org/mobile/). It is also recommended to check the accessibility of the mobile website following W3C's Web Content Accessibility Guidelines 2.0 using a validator such as TAW (http://www.tawdis.net/).

(4) Creating user access to mobile website

There are 2 options for reaching the website (in any case of $a, b$, or c) 
The first one is a mobile device detection script which recognizes the device or the browser from which you access the website and redirects you to the corresponding adapted version automatically.

The other option is to indicate in a visible area of the original that a version for mobile devices is available.

\subsection{Special issues of self development}

The options of self development should be dealt with in more details in the followings. There are 3 major ways of self development (1) through website programming, (2) through free online services, and (3) through application programming.

(1) Self development through Website programming

The website is created using Standards Web programming: HTML5 (this language provides new functionalities for mobile devices programming), XHTML, CSS, etc. The mobile website can be managed using a Content Management System (CMS). An example of this kind of mobile website is that of the Biblioteca Rector Gabriel Ferraté (http:/ / flas.upc.edu/brgf). - The main advantage of our website is that it can be viewed on any mobile device, regardless of its operating system (Android, iPhone OS, etc.). Nevertheless, we need a computer engineer/librarian with the knowledge and the time to create the mobile website. Depending on availability, cost will be higher or lower.

(2) Self development through Free online service

Simply create an account and a website can be created right away. There are a wide range of services available: Ubik, Xtgem, Wirenode, among others. In Spain, Ubik is used by the mobile website of the CSIC Libraries Network (http://bibliotecascsic.ubik.net/). - If this method is chosen no programming skills are needed, it is completely free and mobile website creation is quick and easy. However, there is less flexibility as the source code cannot be modified.

(3) Self development through Application Programming (android, iOS) Libraries such as the Santa Clara County Library and the Seattle Public Library have chosen this option. - Here a completely customized 
application is created which gives programmers the greatest degree of flexibility. On the other hand, application development requires a team of computer engineers and it is necessary to select the device operating system on which the application will work. Application updates also entail further work. Users are already accustomed to using other applications on their mobile devices, so they should have no problem using this type of mobile website. But users still have to download the application, which is a disadvantage.

(4) Issues of computer skills and costs as related to the above options (a), (b) and (c)

In any case, new tools are emerging requiring programming in HTML, allowing for the creation of applications for different platforms. This is the case of PhoneGap, which can be integrated into Dreamweaver CS5.5 (a webpage editing software). Using PhoneGap, developers of mobile device applications are able to write HTML, CSS or JavaScript code, and PhoneGap will automatically create applications for iPhone OS, Android, Symbian, BlackBerry, etc. It should be added that such conversions often lose platform-specific functionalities.

Below is a graph showing the cost and computer skills required for each option:
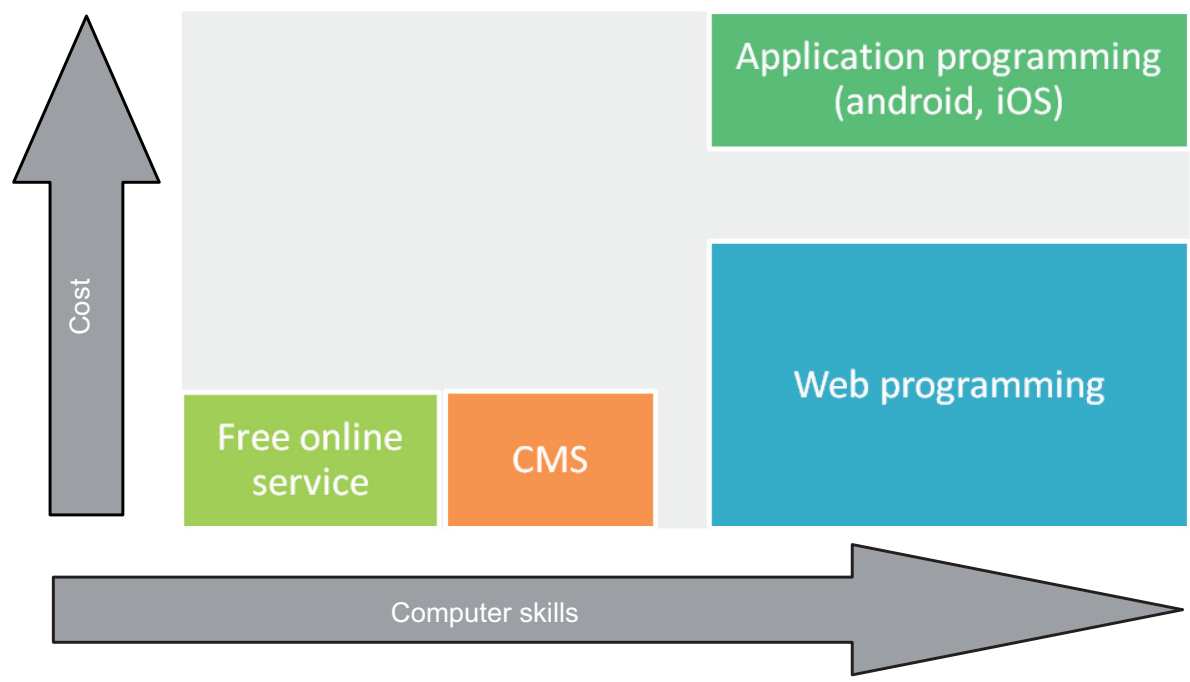


\section{Presenting the UPV library's mobile website}

The mobile was created and introduced in the following steps (3.1.-3.5.)

\subsection{Identifying library contents for the UPV library's mobile website}

Firstly, there is a large amount of information on the library's website. Due to the limited screen space offered by mobile devices and the kind of information that users need when they access via these devices, only some library content was selected:

1. access to the catalog: detailed in the following section

2. custom information: renewals, waiting list, etc.

3. general information: library information and opening times, etc.

4. "la biblioteca responde": virtual reference service

5. electronic resources: access to databases, ebooks, tools, etc. which are adapted by our suppliers free of charge

6. 2.0 tools adapted for mobile devices: Facebook, Twitter, YouTube, blogs...

7. library news

8. a web link to the original website for those users who want access to the non-adapted website.

\subsection{Using the Joomla Content Management System for creating the mobile website}

Secondly, we created the mobile website using a Content Management System (CMS) called Joomla. In this way, users can make use of our mobile website without worrying what kind of mobile device is being used for access. Joomla is completely free and must be installed on a server that uses Apache and MySQL (both of them are free). Three plug-ins were installed on this CMS:

1. Mobile Joomla (http://www.mobilejoomla.com/): automatically adapts website display according to the browser employed in access.

2. My RSS Reader (http://tinyurl.com/c4paqb2): embedded the RSS feed of library news on the mobile website. This means that all news 
on the non-mobile library website is shown on the mobile website automatically.

3. Joom!Fish (http://www.joomfish.net/): this plug-in helps us to manage the languages of the mobile website, which is offered in the Spanish, English and Valencian languages.

Upon completion of this step, BibMòbil (http://bibmobil.upv.es), the UPV library website adapted for mobile devices (Images 1 and 2), was created.

Image 1: Mobile site of the Universitat Polytechnisch de València.

Image 2: Mobile site of the UPV.
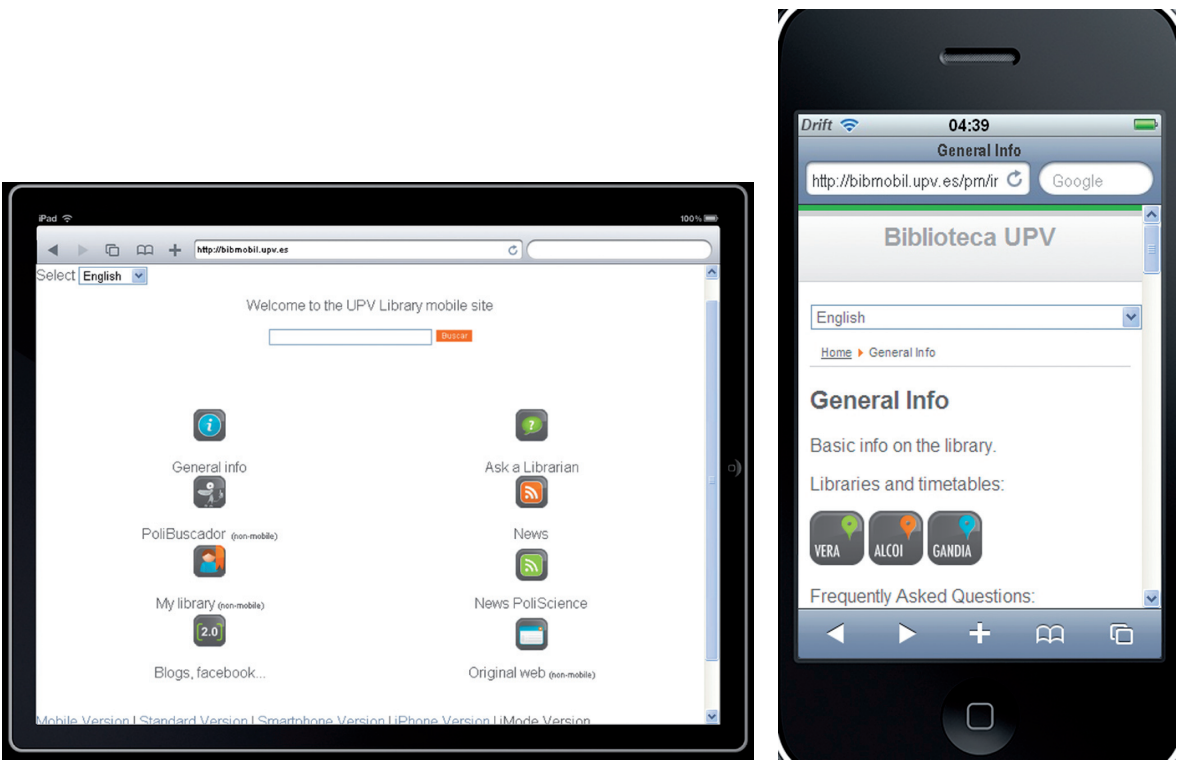

\subsection{Validating the website}

The third step involved the validation of the website pages using the W3C mobileOK Checker to detect and correct mistakes. Most of the pages were found to be at least $75 \%$ mobile-friendly. 


\subsection{Accessing BibMòbil, monitoring and assessing visitors (number, origin, behavior)}

Finally, to access BibMòbil there is a button along with a QR code on the UPV library website homepage. There is also another link to BibMòbil located on the catalog search page.

A Google Analytics account was created to monitor and assess number of visitors, their origin and behavior. The percentage of access is low if it is compared with the number of times the non-mobile website is accessed, however in the last nine months more than 1200 visitors were registered and the average number of pages seen on each visit is 2.46 . The average time taken on each visit is less than 2 minutes, similar to the numbers observed in surveys on mobile user behavior (Ipsos, 2011).

\subsection{Managing the issue of costs of mobile website development}

As we have explained, we must highlight that the cost of the mobile website development is nearly zero because the tools used were free of charge and said development did not require advanced computer skills. The cost of maintenance is almost zero as well, as most of the content is static, and the dynamic content such as news is automatically captured from the library website. Furthermore, the computer maintenance cost is estimated at one week per year, the main reason being the content type and the technology used in developing the mobile website.

\section{4. mOPAC (the mobile OPAC) and its creating}

The mOPAC is the mobile version of OPAC. There are 2 ways to create a mOPAC: creating one from scratch (4.1.) or using commercial tools to create one (4.2.). Both of these options are explained below.

\subsection{Creating it yourself (starting at $€ 0$ )}

This option is a bit complicated because a librarian is needed to define the features of mOPAC; computer engineers are also required in the application development process. 
In Spain there is a mOPAC being used by the Biblioteca Rector Gabriel Ferraté (Image 3) at the UPC. Pérez explains that this option requires the use of a technique called screen scraping (Pérez 2010). The idea here is to reuse data already shown on pages or applications that are running on the conventional website and apply a specific style sheet to facilitate presentation on the mobile website. Thus, with just some "minor" programming, one can create two products in a single step.

\subsection{Using commercial tools}

(1) Innovative Interfaces

This option is the easiest and the most commonly used, but it is also the most expensive. Currently, there are several ILS which offer mOPAC modules:

${ }^{2}$ This firm offers AirPAC (range of prices), that apart from being able to choose between simple and other advanced search functions, allows users to renew items and manage their waiting list. In Spain, there are universities that already offer this product to their users, such as the University of Cádiz (http:/ / diana.uca.es/airpac, Image 4).

Image 3: mOPAC of the Universitat Politècnica de Catalunya.

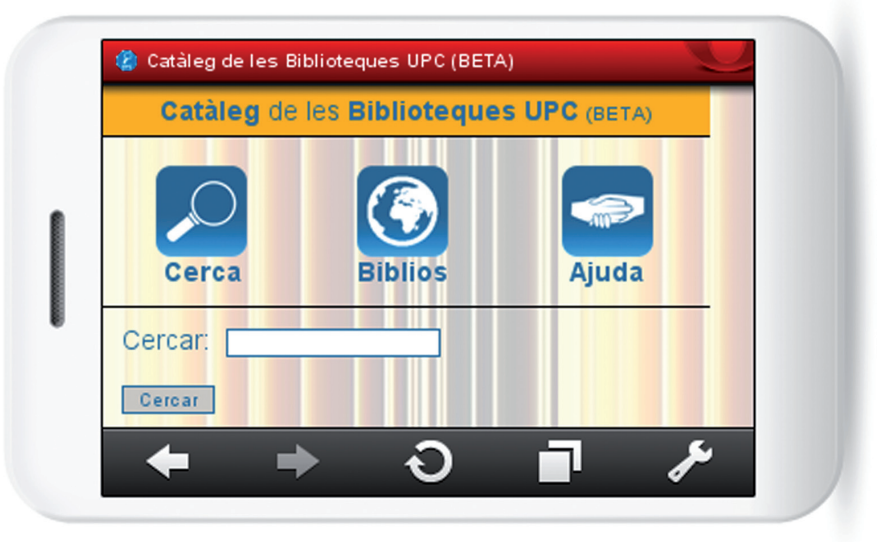


Image 4: $m O P A C$ using AirPAC.

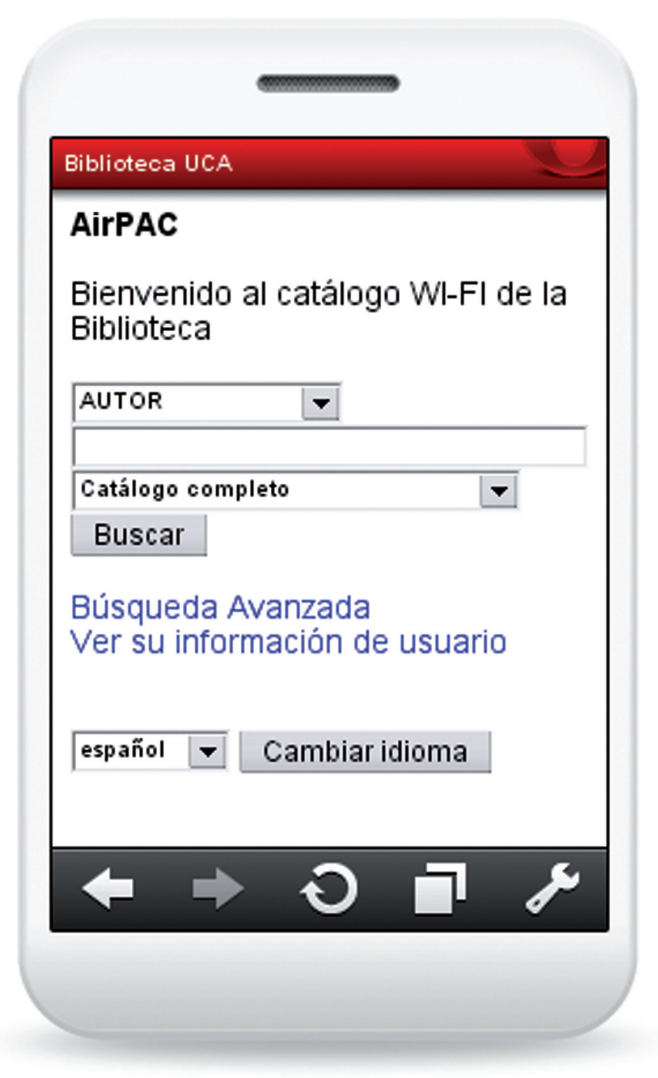

(2) Ex Libris

Ex Libris: The University of Amsterdam uses an application for Aleph, which was presented at the IGeLU meeting held in Ghent in 2010 (Koster \& Popistaşu, 2010). This application is based on a tool developed at the University of Jönköping, that allows users to search on the mOPAC and to make notes on their waiting list (http://m.uba.uva.nl/) (Image 5).

Recently a mobile version of the Primo discovery tool was launched (Image 6) which allows users to search the entire library collection from a mobile device. 
Image 5: mOPAC with Aleph, Amsterdam University Library.

Image 6: Primo for mobile.

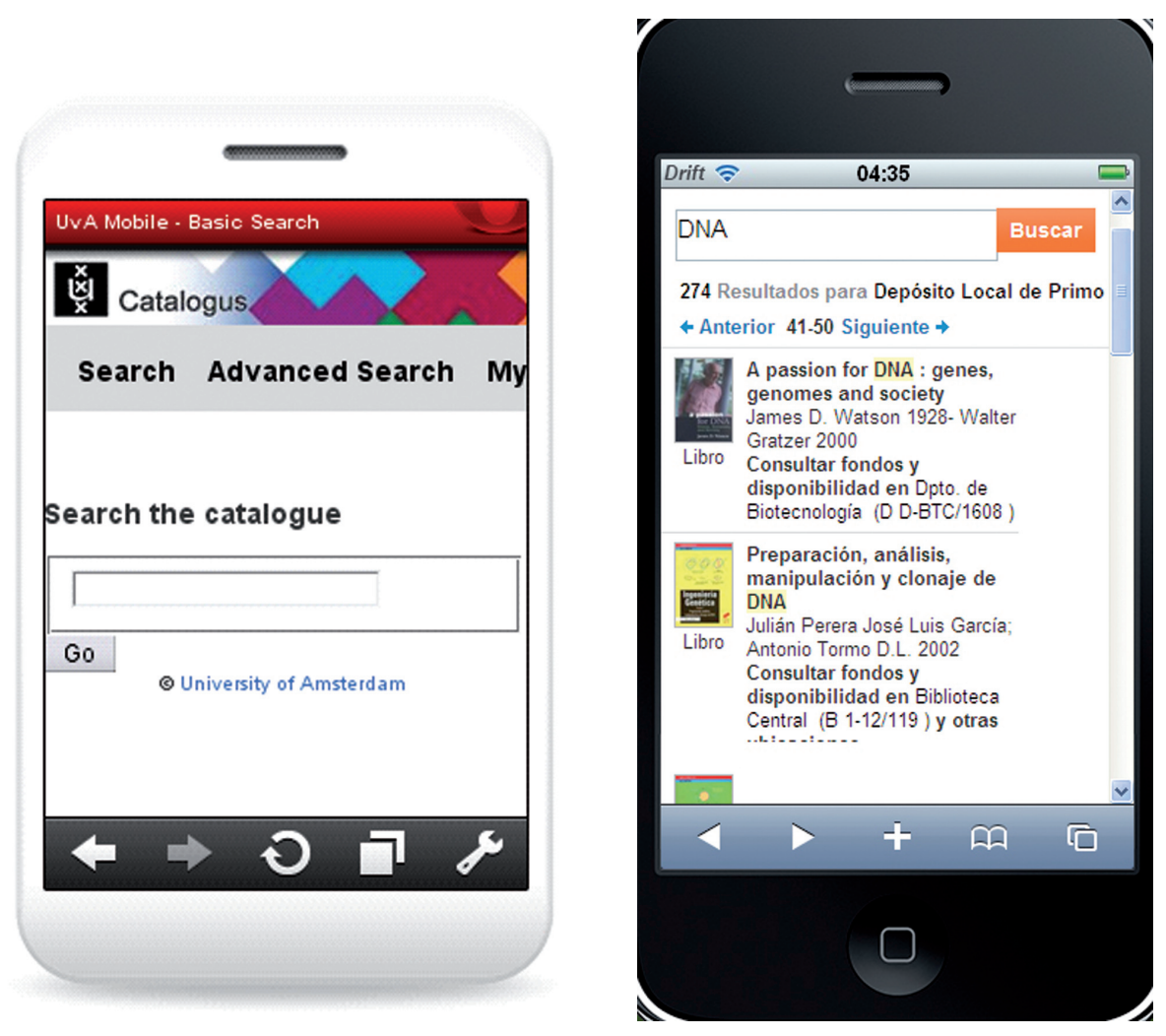

Ex Libris recently launched a new product for its discovery tool Primo, which allows users to correctly visualize the application from different mobile devices such as android or iphone.

Finally, LibraryThing for Libraries offers a module called Library Anywhere (Image 7) that integrates with most commercial ILS. It allows users to search the catalog, manage a waiting list and the list of the books on loan, etc. In addition it does not need installation, LibraryThing for Libraries patrons can access a catalog that includes tags and reviews, recommendations, other issues, etc. 
Image 7: Library Anywhere.



The UPV library recently acquired Primo, Ex Libris' discovery tool. This discovery tool also offers a version for mobile devices (Image 8) which allows users to carry out simple searches in the library catalog, which includes both print and electronic formats.

Although thanks to this tool users can search in the catalog, we are currently working to provide some functionality non-available in Primo "mobile" version, like to search in Primo Central, custom information (renewals, reservations, etc.), purchase orders, etc. 
Image 8: UPV library's mOPAC.



\section{QR Codes: Special issues of creating and applying}

In a mobile web environment, the QR codes (Quick Response) are the tools that enable us to access digital content more easily.

QR codes are square-shaped codes with a black pattern against a white background that can be read by downloadable smartphone readers with camerascanning capabilities (Massis, 2011). These are now found everywhere: in magazines, posters, on websites, videos, newspapers and in advertising. They are frequently used in marketing strategies. Today many libraries have joined 
other institutions which employ those codes. They are really useful in a library context because they can store a lot of information (text, URL, SMS, phone numbers, address details, etc ...) in a small image, providing smartphone users a simple way to obtain information from any location and at any time.

For instance, library users can be given a QR code with the URL of the library's mobile website, making connection to said website easy for users. If you scan the code in Image 9, you will be redirected to the mobile website of the library of the UPV.

Image 9: Example of QR code linking to http://bibmobil.upv.es/.

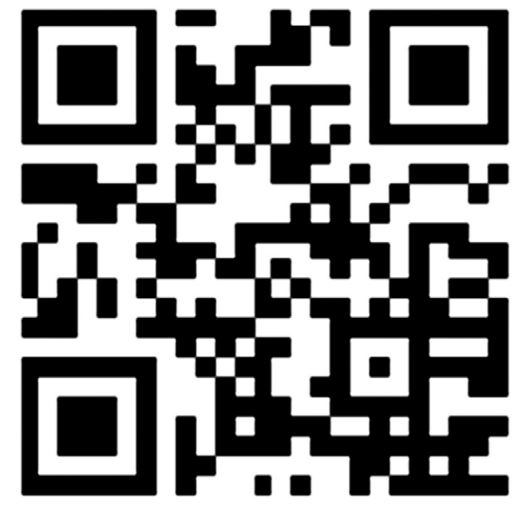

\subsection{Creating and reading $Q R$ codes}

Generating a QR code is very simple process and in some cases it can be generated free of charge. There are numerous websites on which users can create QR codes; some of the most popular are Kaywa, ZXing Project, Treelogic, Delivre, among others.

Most offer basic options displayed on almost all QR generators. Users can add text, URL, addresses, or even a telephone call, or sms message, and other data. There are QR generators which offer a number of design options, such as the Beqrious generator or the Unitag generator. This QR design can be used to attract the attention and interest of potential users (Image 10). 
Image 10: Example of $Q R$ code designed using Unitag linking to http://bibmobil.upv.es/.

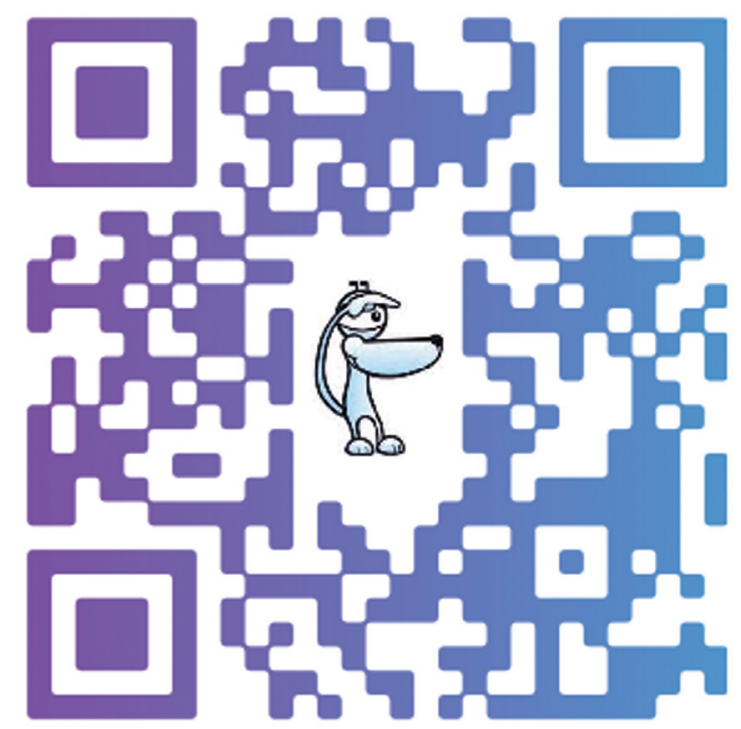

To read a QR code we need a mobile device with a camera and reader software installed.

First we point to the code using a phone with a camera. The camera scans the code and the software decodes it. Finally, we get the information on the screen showing us text, a URL, a phone call, etc...

It is a simple process that offers hundreds of possibilities that can be used on a daily basis, available to libraries at a cost of $€ 0$.

\subsection{The most common QR codes applications for libraries}

QR codes are one of the tools that help smartphone users link physical reality with virtual reality. We can use them on the web, which offers information that can be quickly recovered on our mobile device, or in the real world, where they can lead us to information on the web.

The libraries of the University of Bath and the University of Huddersfield (Walsh, 2010) were pioneers in the use of QR codes. In Spain, QR codes are used by the University of Seville and the UPC. 
These are the most common applications:

1. In OPAC; along with the bibliographic record they give us information about the book details, location, availability...

2. As a link to the library's electronic resources. We can place a QR code next to the document on a physical medium that links to the online resource.

3. They can be useful for training users. For example, near the study rooms, a QR code can provide information about how to use the resources stored therein. A QR located on a shelf of DVDs can provide information on how to search for movies, loan type, etc.

4. Users can contact the referral service through a QR code. Positioned next to the catalogs, they can provide a link to a virtual reference service, by form, by sms or phone.

5. They can be used to geolocate the user on a map of the library, college, etc. indicating the floor and the resources available there.

\subsection{QR codes applications in the UPV libraries}

(1) Introducing using QR codes

The libraries of the UPV are trying to adapt their services to a new environment which is witnessing the growth of the mobile web. One of the tools that is being used is the $Q R$, which allows users an easy way to connect smartphones and library services.

Such as big companies are doing nowadays, UPV libraries are using $\mathrm{QR}$ codes as a marketing tool. They are being used to promote the physical and the digital collection, to share and promote special events and to promote the library services. QR codes are being used to leave relevant information to smartphone users too.

UPV libraries start to use QR codes on 2010 (Pons, Vallés, Abarca \& Rubio, 2011). In the following paragraphs we will show you some examples of how UPV libraries are using QR codes.

(2) Promoting physical and digital collection

In the way to increase the use of the physical collection, UPV libraries used for the first time $\mathrm{QR}$ codes on literacy books reviewed on the blog to promote reading. The blog Connecta't a la lectura is a blog of the 
library where the users can read and comment literacy books reviews from the library to promote reading. To give more visibility to the blog and the literacy collection of the library, a QR code on the cover links the smartphone users to the review on the blog (Image 11).

Image 11: Example of a $Q R$ code in a book.

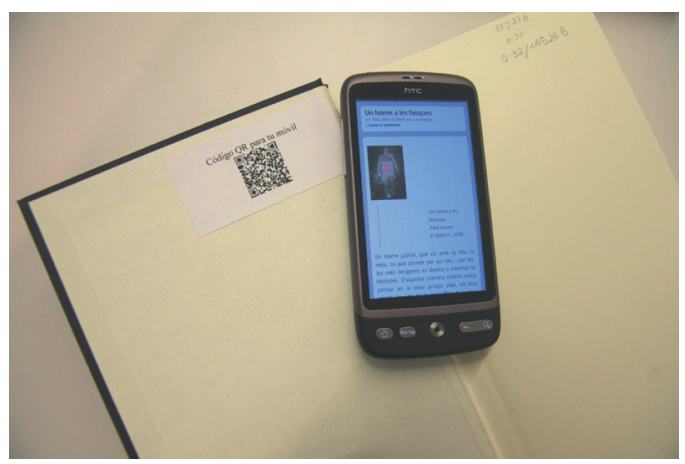

Another example to promote the physical collection is the use of the QR codes linking to a useful query on the catalog. Thus the UPV libraries can promote the parts of the collection that they are interested in image 12 .

Image 12: QR code with URL of a book list.




University libraries have now a digital collection. A big part of the budget of the library is being used to purchase big databases and digital resources. A lot of those resources have a mobile website, so it could be a great idea to share those databases via QR codes to promote the use of those expensive tools. At UPV libraries we are promoting the digital resources putting $\mathrm{QR}$ codes on posters promoting a database or an electronic journal.

(3) Sharing or promoting special events

To share and promote an event the library uses a QR code on posters to link to the website of the event (Blog, Facebook pages, Flickr, library website). As an example, UPV libraries are promoting now new coming events as the "Book Day". A book exhibition was promoted via QR code as we can see in image 13.

Image 13: QR linking to a book exhibition on Flickr.
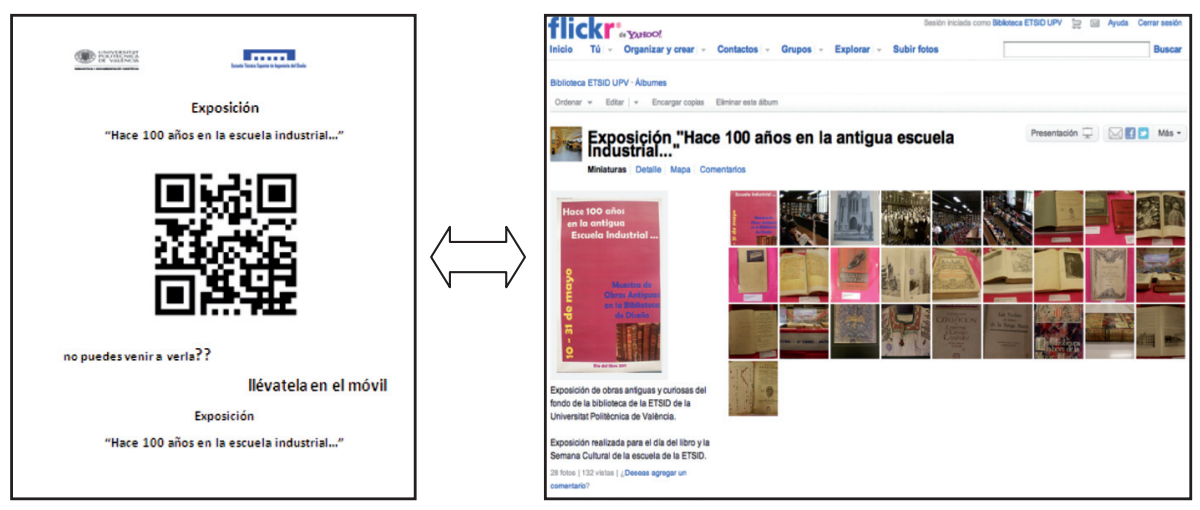

(4) Giving relevant information to the users

Use of QR codes becomes really useful to leave daily information of the library to our users. Some interesting information of the library is shown via QR codes like regular timetables (Image 14). Other examples are QR codes to link to guides and help on the use of different products and services of the library (Image 15), QR with cabinet location in a map or QR with news of the library RSS feed. 
Image 14: QR with URL of timetable.



Image 15: Help guide of the library with $Q R$ code.

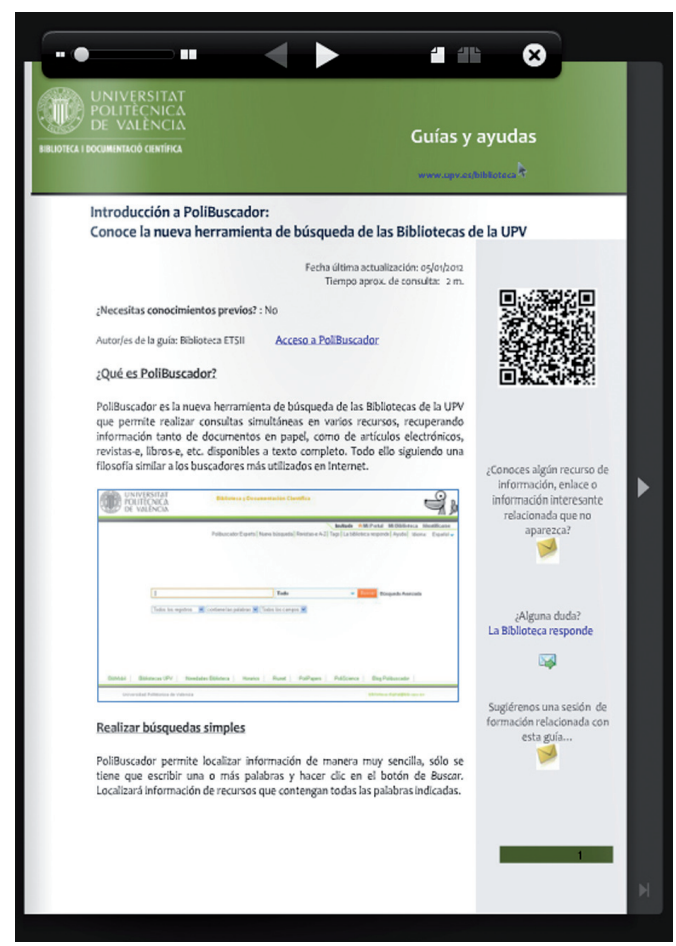


From the examples shown above, some planning is all that is needed to be able to use the QR codes at a given library. It is necessary to study the needs of users and understand the particularities of the library. Imagination is all that is needed to fully exploit what the tool can offer. It's simple, fast and its cost is as little as $€ 0$.

Some users already know about QR codes, but there are still others who have never seen them before. That QR codes are increasingly being used in other University services as well as off campus indicates that users will make use of these codes to a greater extent in the future.

We should not forget that by using QR codes and new technology in the library we are helping to reinforce the library's image of modernity, and to cultivate the idea of the library as being the source of ever-changing, dynamic information without losing sight of technological advances.

Nowadays, we are planning an audio tour of the library or of specific services that would allow, in the manner of those in the museums, to take a guided tour of the library through an audio file that the user would load on his phone through a QR code. This type of guidance could also facilitate the use of library users with visual disabilities.

\section{Augmented reality}

\subsection{Definition}

Augmented reality is not a new concept. Sutherland (1968) started to work in this field in 1968. In 1997, Azuma (1997) defined the difference between virtual reality and augmented reality: in virtual reality "the user cannot see the real world around him. In contrast, augmented reality allows the user to see the real world, with virtual objects superimposed upon or composited with the real world".

With the release of mobile devices that include geolocation information thanks to GPS, a magnetometer which acts as a compass, an accelerometer to detect the angle of the device and a camera, augmented reality has experienced a rebirth, now offering a range of possibilities. Some libraries such 
as North Carolina State University Libraries have begun to use augmented reality services (Ekart, 2011), by way of a historical tour application called WolfWalk. Oregon State University Library has also developed an application called BeaverTracks.

However, the easiest way to implement augmented reality in a library is through library geoinformation (photos, contact information, opening hours, URL to the website, address, etc.). Users run their free augmented reality browser, then search for and select the appropriate layer. The geoinformation of interest is then shown on their mobile device (Image 16). Yet how can we create a layer? And how much does it cost?

Image 16: Augmented Reality application for a mobile device (Photo by STML).

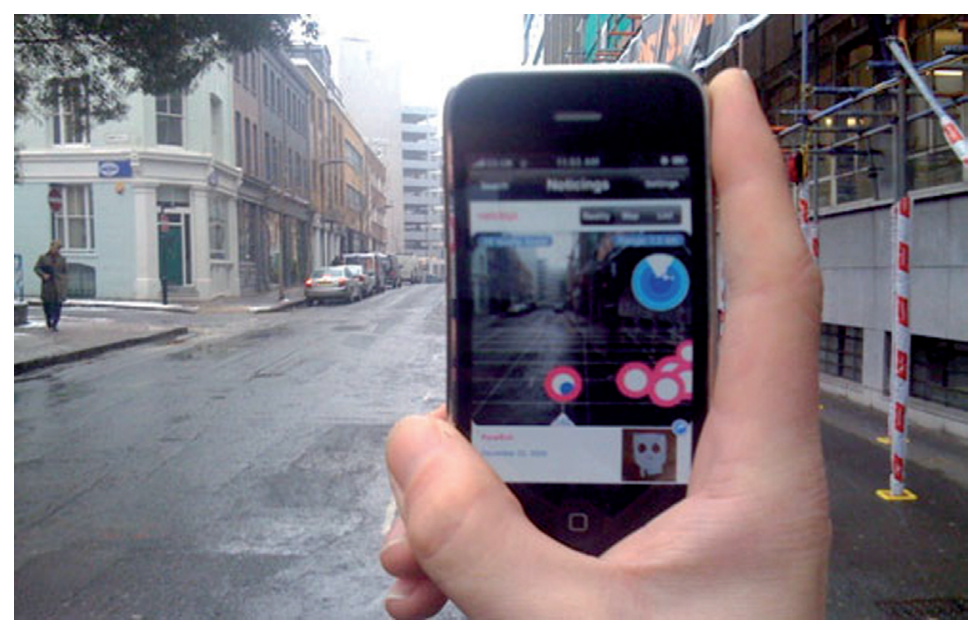

\subsection{Deciding on choosing an augmented reality browser}

The first decision that needs to be made is which augmented reality browser to use, as this should be known in order to create a layer specifically for that particular browser. There are some applications that add these features to social networking applications. Many of the benefits that libraries get from using social networks are equally applicable to the geo-social apps. Two examples of geosocial apps are Foursquare and Google Latitude. Currently 
some augmented reality applications in use are Wikitude (layers of information extracted from sources such as Wikipedia), Junaio (contextual information on locations and augmented reality applied to printed paper) or Google Latitude.

However, the main augmented reality browser is Layar. This application has been installed more than 10,000,000 times and has more than 4,400 layers.

\subsection{Options of developing a layer in Layar}

There are two options to create a layer in Layar: create a layer hosted on the library's own server or use a free online tool. Both options are free, however each has its own set of advantages and disadvantages.

(1) A layer on the own server:

With Layar, you can create your own layer using their development platform. The first step is to register as a developer, then install and parameterize the modules provided by Layar. To install these modules, you need a web server, and it is also necessary to install and configure the source code.

There are two advantages when choosing this option. Firstly, you will use the source code provided by Layar, thus full compatibility is ensured whilst taking advantage of the application's current and future features. The layer that is created is hosted on the library's server so you do not need to rely on a third party.

On the other hand, this option requires the presence of a computer engineer. However, it is assumed that only a few days of work are needed to set up the system and enter the information.

Other option is PorPOISe, a server for Layar clients. This server features a graphical interface which will help you create your layers. The latest version of PorPOISe offers all the features available in Layar. The graphical interface gives this server an advantage over the previous option, since data entry is easier. Its other advantages and disadvantages are similar. 
(2) A layer on an external server

We can create a layer using free online tools, like Hoppala, Poistr, Visar, etc. The main advantage of using these tools is that no computer skills are needed. Furthermore, creating a layer is quick and easy. For instance, if you create a layer using Hoppala, it can be accessed by a number of augmented reality browsers such as Layar, Junaio and Wikitude.

The one disadvantage when using an external server is that it is not directly controlled by the library. The implication here is that if the external server fails our layer will also fail.

\subsection{Augmented reality in the UPV library}

We have decided to create a layer layar to reach these goals:

1. To facilitate the physical location of our facilities, because we have our libraries in different buildings

2. To attract users

3. To increase access to our websites from our physic location

4. To establish a new way of relation with the user

At present, we are evaluating our resources and holding discussions on the best option for layer creation for our library, as well as determining the content that will be included. We plan to make the layer available in the near future.

\section{Conclusions}

There are many advantages to the use of ICT in library management (ranging from ILS, to Discovery Tools as well as RFID technologies). These tools save time and library staff-hours, and allow for the creation of new value-added services. We believe that communication with the user is the service that has most benefitted from the implementation of these tools. The creation of profiles on social networking websites, the use of digital signage and thematic blogs, etc. are just some of the ways in which we are now communicating with patrons; more than just a current fashion, these technologies help us to better understand user needs and preferences. 
The expansion of mobile devices (smartphones, tablets, e-readers, etc.), along with the spread of Wi-Fi and 3G/4G networks, opens up a field of experimentation and improvement that offers many possibilities for development that are economically viable. As we have seen, many of these technologies cost next to nothing and in many cases, time is the only resource that is required.

With an ever-growing impact of mobile devices on learning, as shown by Quinn (2011), who advocates the use of mobile devices in the learning process and the importance of creating a mobile learning strategy.

Likewise, we have to change our mentality regarding the use of mobile devices in the library; these tools are much more than mere telephones and are routinely used to store information, check email or even as research tools (Torres Salinas, 2011). That is why the Rules published by the UPV Library no longer bar the use of mobile phones; patrons are only asked to mute ring tones and ensure that they do not speak out loud when using their phones.

We cannot ignore the way users communicate. Some of our users are already operating in a mobile communication environment and sooner or later the rest will join them. This does not mean that we should be always where they are and use all these tools, or other future tools, but we must be aware of their existence and usefulness.

Furthermore, large service and scientific content providers such as Elsevier, ProQuest, EBSCO, Emerald or even Google are showing greater interest in adapting their services to this new reality. We believe that libraries should move in this same direction.

It is also important to realize that working with these technologies is more akin to working in clay than stone, which means that we should not be afraid of making mistakes. Perhaps now is the time to look to cheaper and more versatile solutions (Margaix Arnal, 2010).

\section{References}

Aldrich, A. W. (2010). Universities and libraries move to the mobile web. Educause Quarterly Magazine, 33(2). Retrieved May 30, 2012 from http://tinyurl.com/25xlzpr.

Arroyo Vázquez, N. (2009). Web móvil y bibliotecas. El profesional de la información, 18, 129-136. Retrieved May 30, 2012 from http://hdl.handle.net/10760/13057. 
Arroyo Vázquez, N. (2010). Web móvil y bibliotecas [Slideshow], 2010, July 9. Retrieved May 30, 2012 from http://www.slideshare.net/natalia.arroyo/web-mvil-ybibliotecas.

Azuma, R. T. (1997). A survey of augmented reality. Presence: Teleoperators and Virtual Environments, 6, 355-385. Retrieved May 30, 2012 from http://www.cs.unc. edu/ azuma/ARpresence.pdf.

Cummings, J., A. Merrill and S. Borrelli (2010). The use of handheld mobile devices: their impact and implications for library services. Library Hi Tech, 28, 22-40. doi: 10.1108/07378831011026670. Retrieved May 30, 2012 from http://hdl.handle. net $/ 2376 / 2325$.

Ekart, D. F. (2011). Augmenting your reality. Computers in Libraries, 31, 34-35.

Havelka, S. and A. Verbovetskaya (2012). Mobile information literacy: let's use an app for that! College E Research Libraries News, 73, 22-23. Retrieved May 30, 2012 from http://crln.acrl.org//content/73/1/22.

Iglesias, E. and W. Meesangnil (2011). Mobile web website development: from site to app. Bulletin of the American Society for Information Science and Technology, 38, 18-23 Retrieved May 30, 2012 from http://tinyurl.com/6sv6cbk.

Ipsos MediaCT (2011). Think mobile [Slideshow]. Retrieved May 30, 2012 from http:// www.slideshare.net/duckofdoom/google-research-about-mobile-internet-in-2011.

Koster, L. and R. Popistaşu (2010). UBA mobile [Slideshow]. Retrieved May 30, 2012 from http:/ / www.slideshare.net/lukask/uba-mobile-igelu-2010.

Margaix Arnal, D. (2010) Tecnologías plastilina; tecnologías mármol. Retrieved May, 2012 from http://tinyurl.com/7yugeew.

Massis, B. E. (2011). QR codes in the library. New Library World, 112, 466-469. doi:10.1108/03074801111182058.

Meeker, M., S. Devitt and L. Wu (2010). Internet Trends [Slideshow]. Retrieved May 30, 2012 from http://www.morganstanley.com/institutional/techresearch/pdfs/ MS Internet Trends 060710.pdf.

Paterson, L. and B. Low (2011). Student attitudes towards mobile library services for smartphones. Library Hi Tech, 29, 412-423. doi: 10.1108/07378831111174387.

Pérez, A. (2010). Y si nos movilizamos?. (Utilidades de la web móvil para profesionales de la información). Retrieved May 30, 2012 from http://comunidad20.sedic. es/?p=327.

Pons, D., R. Vallés, M. Abarca and F. Rubio (2011). QR codes in use: the experience at the UPV Library. Serials: The Journal for the Serials Community, 24, S47-S56. doi: $10.1629 / 24 S 47$. 
Sutherland, I. (1968). A Head-Mounted Three-Dimensional Display. Fall Joint Computer Conf., Am. Federation of Information Processing Soc. (AFIPS) Conf. Proc. 33, 757-764.

Thomas, L. C. (2012). Mobile libraries 2012. Library Journal, 137, 26-28.

Torres Salinas, D. (2011) Aplicaciones de los smartphones y la web móvil en la ciencia y la investigación. EC3 noticias. Retrieved May 30, 2012 from http://tinyurl.com/ dyfcqvk.

Travis, T. and A. Tay (2011). Designing low-cost mobile websites for libraries. Bulletin of the American Society for Information Science and Technology, 38, 24-29. Retrieved May 30, 2012 from http://www.asis.org/Bulletin/Oct-11/OctNov11Travis Tay.pdf.

Walsh, A. (2010). QR Codes - using mobile phones to deliver library instruction and help at the point of need. Journal of Information Literacy, 4, 55-64. Retrieved May 30, 2012 from http://tinyurl.com/3a9qdql.

\section{Note}

${ }^{1}$ Costs do not include library staff costs and the cost of the facilities (electricity, computers, etc.). 